\title{
FABRICATION OF CERAMIC COMPOSITES: FORCED CVI
}

\author{
Theodore M. Besmann, Jerry C. McLaughlin, and Hua-Tay Lin \\ Metals and Ceramics Division \\ Oak Ridge National Laboratory, Oak Ridge, TN
}

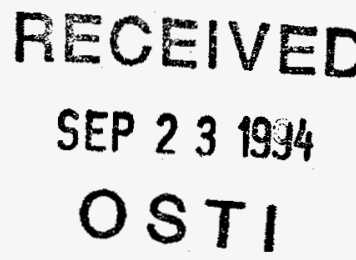

Forced chemical vapor infiltration (CVI) is being developed as an efficient means for producing thick-wall ceramic matrix components. Recent efforts have focussed on process scale-up, modeling and the properties of the resultant material. Disks $24.6 \mathrm{~cm}$ in diameter and $1.27 \mathrm{~cm}$ thick have been produced. Composites of Nicalon ${ }^{\mathrm{TM}}$ fibers and $\mathrm{SiC}$ matrix have exhibited $480 \mathrm{MPa}$ strength in flexure.

Key words: chemical vapor infiltration, forced chemical vapor infiltration, CVI, FCVI, ceramic composites, mechanical properties of ceramic composites, ceramic composite processing

\section{DISCLAIMER}

This report was prepared as an account of work sponsored by an agency of the United States Government. Neither the United States Government nor any agency thereof, nor any of their employees, makes any warranty, express or implied, or assumes any legal liability or responsibility for the accuracy, completeness, or usefulness of any information, apparatus, product, or process disclosed, or represents that its use would not infringe privately owned rights. Reference herein to any specific commercial product, process, or service by trade name, trademark, manufacturer, or otherwise does not necessarily constitute or imply its endorsement, recommendation, or favoring by the United States Government or any agency thereof. The views and opinions of authors expressed herein do not necessarily state or reflect those of the United States Government or any agency thereof. 


\section{DISCLAIMER}

Portions of this document may be illegible in electronic image products. Images are produced from the best available original document. 


\title{
FABRICATION OF CERAMIC COMPOSITES: FORCED CVI
}

\author{
Theodore M. Besmann, Jerry C. McLaughlin, and Hua-Tay Lin \\ Metals and Ceramics Division \\ Oak Ridge National Laboratory, Oak Ridge, TN
}

\section{Introduction}

The past decade has seen the development of the forced flow-thermal gradient chemical vapor infiltration (FCVI) process as an alternative to isothermal-isobaric chemical vapor infiltration (ICVI) to meet differing structural composite requirements. Whereas ICVI can efficiently produce thin-wall, complex-shape parts, it requires a significantly long time to produce thicker-wall materials (>3 mm). Using ICVI for thicker components requires many weeks to months of infiltration time, interrupted by occasional machining of the surfaces to open gas pathways that have become sealed due to overcoating. The FCVI of thicker sections can be effected in a single step and at sufficiently high rates to only require tens of hours or less.

In ICVI the reactant gases are allowed to flow around the preform and diffuse into the inner volume. In FCVI the reactant stream is forced to flow through the preform, thus only depending on diffusion to reach the finest porosity within, for example, fiber bundles. The imposition of a thermal gradient prevents premature sealing of the gas entrance surface, thus obviating the need for surface machining. Details of the processes have been extensively described elsewhere.[1-6]

The objective of the reported work was to scale-up the Oak Ridge National Laboratory (ORNL) FCVI technique to demonstrate fabrication of components approaching $30 \mathrm{~cm}$ in width and $2.5 \mathrm{~cm}$ in thickness. Previously, systems were available with capability to produce materials with a diameter of only $7.6 \mathrm{~cm}$. The effort was designed as a demonstration of the ease of scaling the process and to provide for a comparison of the produced components with those prepared by other means.

This paper is an account of the scale-up FCVI unit specifications and the resultant infiltration system that was manufactured. The preform selected for the demonstration, a turbine rotor subelement prepared from a polar weave preform, is described along with the results of infiltration, including non-destructive evaluation and testing of the components. Additional efforts were undertaken to determine the mechanical properties of a densified cloth layup preform.

\section{Scale-up FCVI facility}

The specifications for the scale-up FCVI unit included requirements such as hot and cool surface temperatures and their control, minimal radial gradients, instrumentation, 
and exhaust gas cleaning. These are indicated below:

Heating: Hot surface minimum temperature of $1500^{\circ} \mathrm{C}$

Radial gradients $<10^{\circ} \mathrm{C}$

Variable cooling of cool surface

Fixturing: Hold preform shape

Capacity to $30 \mathrm{~cm}$ diameter $\times 2.4 \mathrm{~cm}$ thickness

Exclude reactants from heating elements

Instrumentation: Measure diametral temperature profile

Meter reactant flow

Measure reactant inlet pressure

Monitor power to heating elements

Provide for automated ramp to temperature and shut-down

Computer interface for data acquisition and control

Exhaust gas: Recirculating caustic scrubber

Explosive gas dilution

3. FCVI system

The furnace and power supply components of the FCVI system were designed and constructed by Advanced Vacuum Systems of Ayer, MA. Figure 1 is a schematic of the furnace with the important features indicated. The furnace shell and lid are watercooled. Access is gained through the top lid which rises on pneumatic lifters. The inside of the lid contains two concentric heating elements which are independently controlled, and therefore allow control of the radial temperature gradient. Also in the lid are two pneumatic hold-down pins, which press down on the preform fixture to compress the preform and seal the fixture against reactant gas leakage into the furnace cavity. The reactant gas inlet fits into the bottom of the fixture and the exhaust exits the fixture through a graphite tube that mates with a metal exhaust line. Graphite foil is used as gasket material in the fixture and to help seal the gas entrance and exhaust tubes.

The bottom surface can be cooled with either a water-cooled plate or with forced air blown through annuli below the furnace. A baffle is fixed such that the flow of air can be directed to varying degrees into the inner or outer annulus, thus allowing control over the lower surface radial gradient. Temperature measurement is via thermocouples that are emplaced above and below the preform fixture (six each). Temperatures are maintained utilizing control thermocouples on the hot side (controlling power to the heating elements) and on the cool side (controlling positioning of the air flow baffle). 
The remaining system components were assembled on site. Reactant flow control is via a Tylan (Torrance, CA) Source $V$ vapor source for methyltrichlorosilane (MTS) and MKS (Andover, MA) mass flow meters for hydrogen. Inlet reactant stream pressure is measured with a MKS Baratron. A caustic wet scrubber supplied by Vanair (Louisville, KY) was used for neutralizing the exhaust gas, which was previously diluted with air below the lower explosive limit for hydrogen. Figure 2 is a photograph of the system together with two infiltrated disks.

\section{Preforms}

The preforms used for demonstrating scale-up were constructed of a modified polar weave fabric developed for the U.S. Air Force Wright Laboratory "High Temperature, Non-Metallic Turbine Engine Evaluation" program under Allied-Signal Corp. (Phoenix, AZ) by Textile Technologies Inc. (Hatboro, PA). The preform was designed for a turbine engine compressor subelement and is $24.6 \mathrm{~cm}$ in diameter and $1.27 \mathrm{~cm}$ thick, with a $1.27 \mathrm{~cm}$ diameter central hole. The Allied-Signal program utilized preforms with a satin weave containing a glass matrix prepreg added to the fibers before weaving. However, the FCVI preforms required no prepreg, and it was observed that the use of the satin weave without prepreg resulted in inadequate fiber loading. The weave was thus modified to a plain weave, which yielded satisfactory preforms. The resultant fiber loading was $\sim 33 \%$.

Subsequent to the demonstration phase of the effort, a composite disk was produced for more extensive mechanical properties testing. A similar dimension preform of plain weave Nicalon $^{\mathrm{TM}}$ cloth was laid up using 55 layers of cloth, oriented $\pm 30^{\circ}$.

For all preforms the sizing (i.e., the organic coating on as-received fiber tows) was removed by heating in the furnace, and this step was followed by the deposition of $-200 \mathrm{~nm}$ of pyrolytic carbon on the fibers. This was accomplished by placing the preform in the FCVI furnace and holding the top surface temperature at $1100^{\circ} \mathrm{C}$, the pressure fixed at $6.6 \mathrm{~Pa}$, and flowing propylene diluted in argon through the preform. After two hours the furnace was shut-down and the preform turned over. The process was then repeated. This ensured that the coating was applied uniformly throughout the preform. Weight gain measurements confirmed the average coating thickness.

\section{Densification}

The preforms were infiltrated utilizing constant flows of $5 \mathrm{~g} / \mathrm{min} \mathrm{MTS}, 5 \mathrm{l} / \mathrm{min} \mathrm{H}_{2}$, and a hot surface temperature of $1200^{\circ} \mathrm{C}$, and required $\sim 40 \mathrm{~h}$. The results are shown in Table I.

6. Spin Testing 
The polar weave composites were spin tested to determine their strength in potential turbine rotor environments. The results of spin testing performed at Williams International, Inc. (Walled Lake, MI) were inconclusive due to eccentricities in the densified preforms. Specimen no. 2 was spun up to $21,080 \mathrm{rpm}$ and became unstable, causing shearing of the mounting quill. (The equivalent stress was $193 \mathrm{MPa}$.) The disk struck the wall of the spin test pit, yet remained intact. A second test was performed with the same disk which again sheared the quill at 20,850 rpm, indicating a destructive harmonic at that speed. This time the disk delaminated due to striking the edge of the groove left in the lead wall by the first test.

Specimen no. 3 was designed to overcome the test problems encountered with no. 2 . The disk was made thinner to allow the test rig to overcome any imbalance. In addition, the holes in the fixture top plate were made smaller to reduce puckering in the cloth. This specimen, however, proved to have an eccentric placement of the center hole which caused the disk to encounter a critical point at 14,700 rpm, stalling the apparatus. The disk was intact, but only tested to $70.2 \mathrm{MPa}$.

\section{Characterization Procedures}

Characterization studies were conducted on test bars taken from sections cut from a composite disk prepared as a cloth layup (no. 4). The disk was cut into sections $45 \mathrm{~mm}$ long and labeled I through V (Fig. 3). Sections II through $V$ were then cut into four plates and labeled as shown. The top layer refers to the position in the FCVI furnace that is nearest the heating elements. Each plate was then cut into $3 \mathrm{~mm} \times 4 \mathrm{~mm} \times 45$ $\mathrm{mm}$ bend bars labeled as shown in Fig. 3. This allows one to reference each bar to its exact position within the FCVI disk.

Bars were randomly selected from each layer and density measurements made using the Archimedes method to obtain closed porosity and geometric (bulk) density to determine the sum of open and closed porosity. After drying, the effectiveYoung's modulus was measured for each bar by using an impulse excitation technique. This technique measures the resonant frequency of bend bars by exciting them mechanically with a singular elastic impulse. A transducer (contact accelerometer) senses the resulting mechanical vibrations of the bend bars and transforms them into electrical signals. The resonant frequencies, dimensions, and mass of the bend bars were then used to calculate the effective Young's modulus. Fifteen measurements were made for each bar to obtain an average value. The flexural strength as a function of specimen density at $300^{\circ} \mathrm{C}$ in air ( $-50 \%$ relative humidity) was characterized in fourpoint bending ( $20 \mathrm{~mm}$ inner span versus $40 \mathrm{~mm}$ outer span) under a loading rate of $\sim 40$

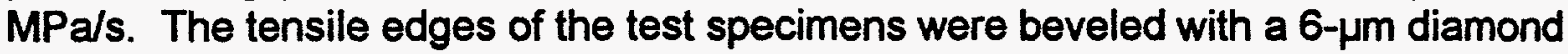
polishing lap. 


\section{Mechanical Properties}

Figure 4 shows the results of both Archimedes and geometric densities as a function of bend bar position through the thickness and diameter of the FCVI disk. The closed porosity (Archimedes density) is reasonably constant through the thickness, with the specimens from the bottom layer having a slightly higher closed porosity. However, there was considerable variation in the open porosity that appeared generally as large, incompletely filled spaces in the open structure of the cloth weave or between cloth layers. Specimens from the bottom layer had open porosity levels of 10 to $15 \%$. The specimens from the second and third layers had the lowest open porosity $(<6 \%)$ and the porosity level in the top layer specimens were between these two extremes.

Measurements of the effective Young's modulus are shown in Fig. 5 as a function of the bulk density. As expected the modulus increases linearly with the density. As a result, the fracture strength in four-point flexure should also decrease with increase in open porosity, and this is seen in Fig. 6 . In the present study, these variations in mechanical properties with density can be correlated with the position in the section of the FCVI disk; the highest densities, Young's modulus, and strength being associated with the two layers located in the central plane (with respect to the thickness) of the disk. The bottom layer exhibits the lowest values for these characteristics, and the top layer has values that lie between these extremes.

\section{Conclusions}

The demonstration of scale-up in FCVI was successfully accomplished with the fabrication of 24-cm diameter disks. The Tyranno ${ }^{T M}$ polar-weave preforms were relatively well-infiltrated, with spin-test strengths of at least $\sim 200 \mathrm{MPa}$. A Nicalon ${ }^{\mathrm{TM}}$ cloth layup preform was densified, sectioned, and characterized with respect to density. The specimens' mechanical properties of Young's modulus and flexural strength were found to be proportional to density. The most dense specimens ( $10 \%$ void volume) were found to have an effective modulus of $\sim 240 \mathrm{GPa}$ and a flexural strength of $\sim 480$ $\mathrm{MPa}$. 


\section{ACKNOWLEDGEMENTS}

The authors would like to thank B. Draskovitch of Allied Signal for help in obtaining the polar-weave preforms, M. Battison of Williams International for performing the spin tests, and B. E. Foster of ORNL for the non-destructive evaluation work. A.A. Wereszczak and L.L. Snead of ORNL provided valuable comments on the manuscript. The authors would also like to thank H. R. Livesey for help in preparing the graphics and J. Z. Palmer for help in preparing the text. The research was sponsored by the Air Force Wright Laboratory, Wright-Patterson Air Force Base, OH, MIPR FY1457-92N5036, U.S. Department of Energy Interagency Agreement 1692-B081-A1 and by the U.S. Department of Energy, Assistant Secretary for Energy Efficiency and Renewable Energy, Office of Industrial Technology, Improved Energy Productivity Division and the Advanced Industrial Materials Program, under contract DE-AC05-84OR21400 with Martin Marietta Energy Systems, Inc.

\section{REFERENCES}

1. E. Fitzer and R. Gadow, Ceram. Bull. 65 [2] (1986) 326.

2. R. Naslain, J. Alloys and Compounds 188 (1992).

3. J. Y. Rossignol, F. Langlais, and R. Naslain, in Proc. 9th Int'l. Conf. CVD, eds. McD. Robinson et al. (The Electrochemical Society, Pennington, New Jersey 1984) p. 596.

4. D. P. Stinton, A. J. Caputo, and R. A. Lowden, Ceram. Bull. 65 [2] (1986) 347.

5. T. M. Besmann, B. W. Sheldon, R. A. Lowden, and D. P. Stinton, Science 253 (1991) 1104.

6. T. D. Gulden, J. L. Kaae, K. P. Norton, and L. D. Thompson, in Proc. 11th Int'I. Conf. CVD, eds. G. W. Cullen and K. E. Spear (The Electrochemical Society, Pennington, New Jersey 1990) p. 546. 
Table 1. Results of the infiltration runs.

\begin{tabular}{|c|c|c|c|c|c|}
\hline Spec. No. & $\begin{array}{l}\text { Weavel } \\
\text { Fiber }\end{array}$ & $\begin{array}{l}\text { No. } \\
\text { Plies }\end{array}$ & $\begin{array}{l}\text { Thickness } \\
(\mathrm{cm})\end{array}$ & $\begin{array}{l}\text { Run Time } \\
\text { (h) }\end{array}$ & $\begin{array}{l}\text { Void } \\
\text { Fraction }\end{array}$ \\
\hline 1 & $\begin{array}{l}\text { Polar/ } \\
\text { Tyranno }\end{array}$ & 50 & 1.59 & 40 & $16.5 \%$ \\
\hline 2 & $\begin{array}{l}\text { Polarl } \\
\text { Tyranno'm }\end{array}$ & 50 & 1.59 & 40 & $16.4 \%$ \\
\hline 3 & $\begin{array}{l}\text { Polarl } \\
\text { Tyranno }\end{array}$ & 40 & 1.27 & 40 & $13.6 \%$ \\
\hline 4 & $\begin{array}{l}\text { Plain/ } \\
\text { Nicalon }\end{array}$ & 55 & 1.59 & 51 & $15.3 \%$ \\
\hline
\end{tabular}




\section{FIGURE CAPTIONS}

Figure 1. FCVI furnace schematic for large-scale component fabrication

Figure 2. Photograph of the FCVI furnace with two infiltrated disks.

Figure 3. Plan for sectioned Nicalon ${ }^{\mathrm{TM}} / \mathrm{SiC}$ composite.

Figure 4. Open and closed porosity in the sectioned specimens for the various of layers.

Figure 5. Measurements of effective Young's modulus as a function of density.

Figure 6. Flexure strengths as a function of density. 


\section{FCVI System Allows Rapid Densification of Composites}

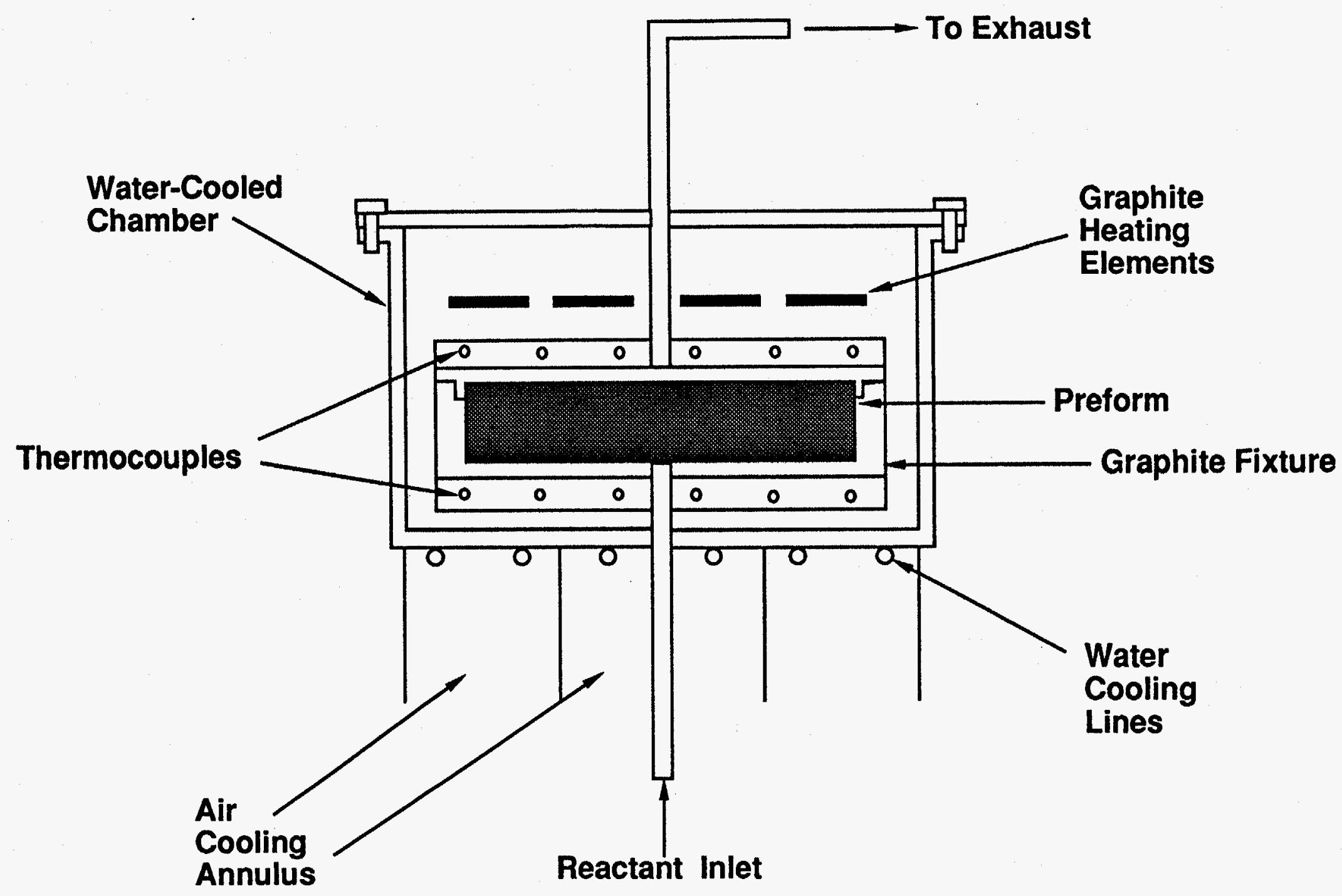


1

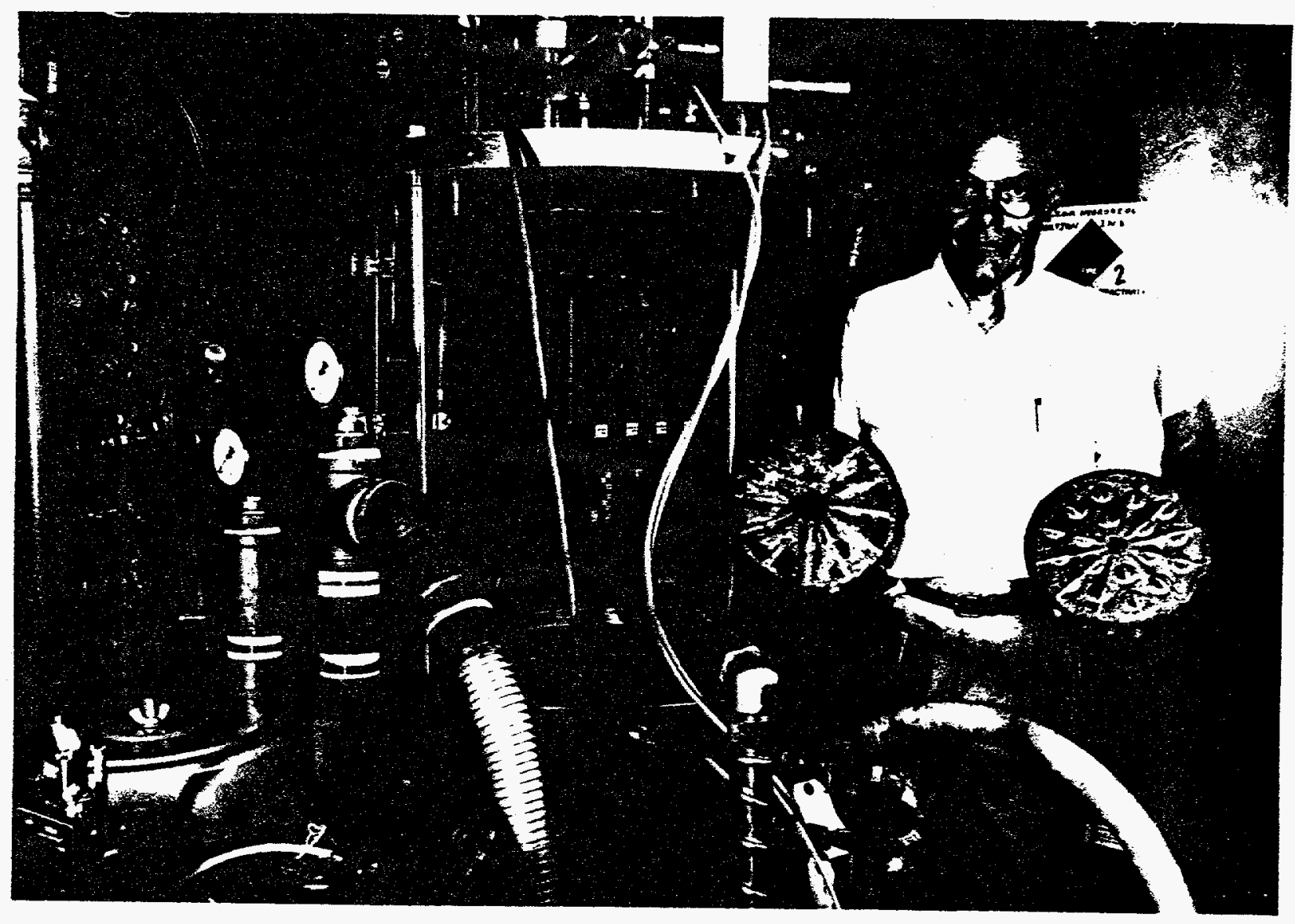




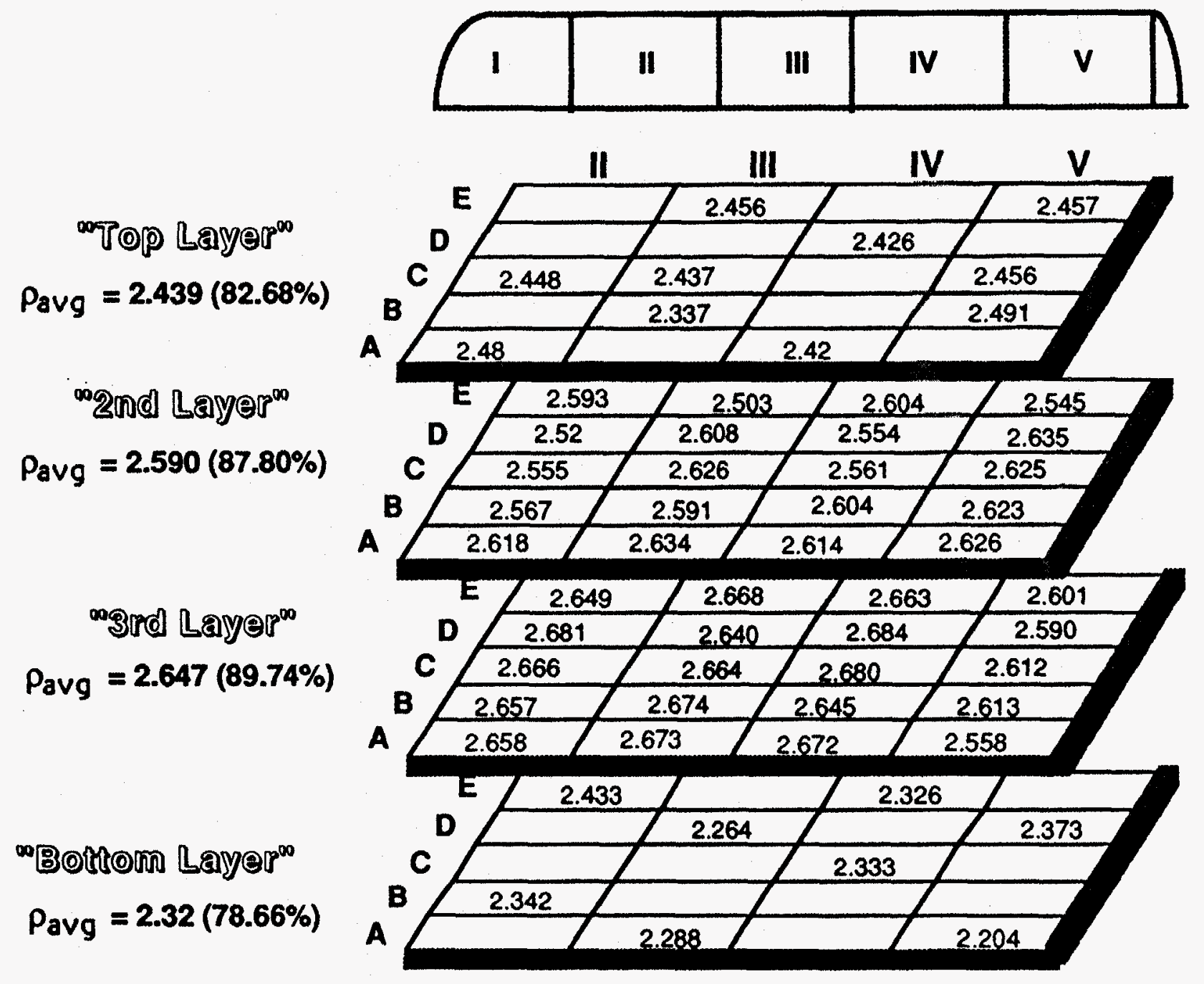




\section{VOID VOLUME DISTRIBUTED BETWEEN OPEN AND CLOSED POROSITY}

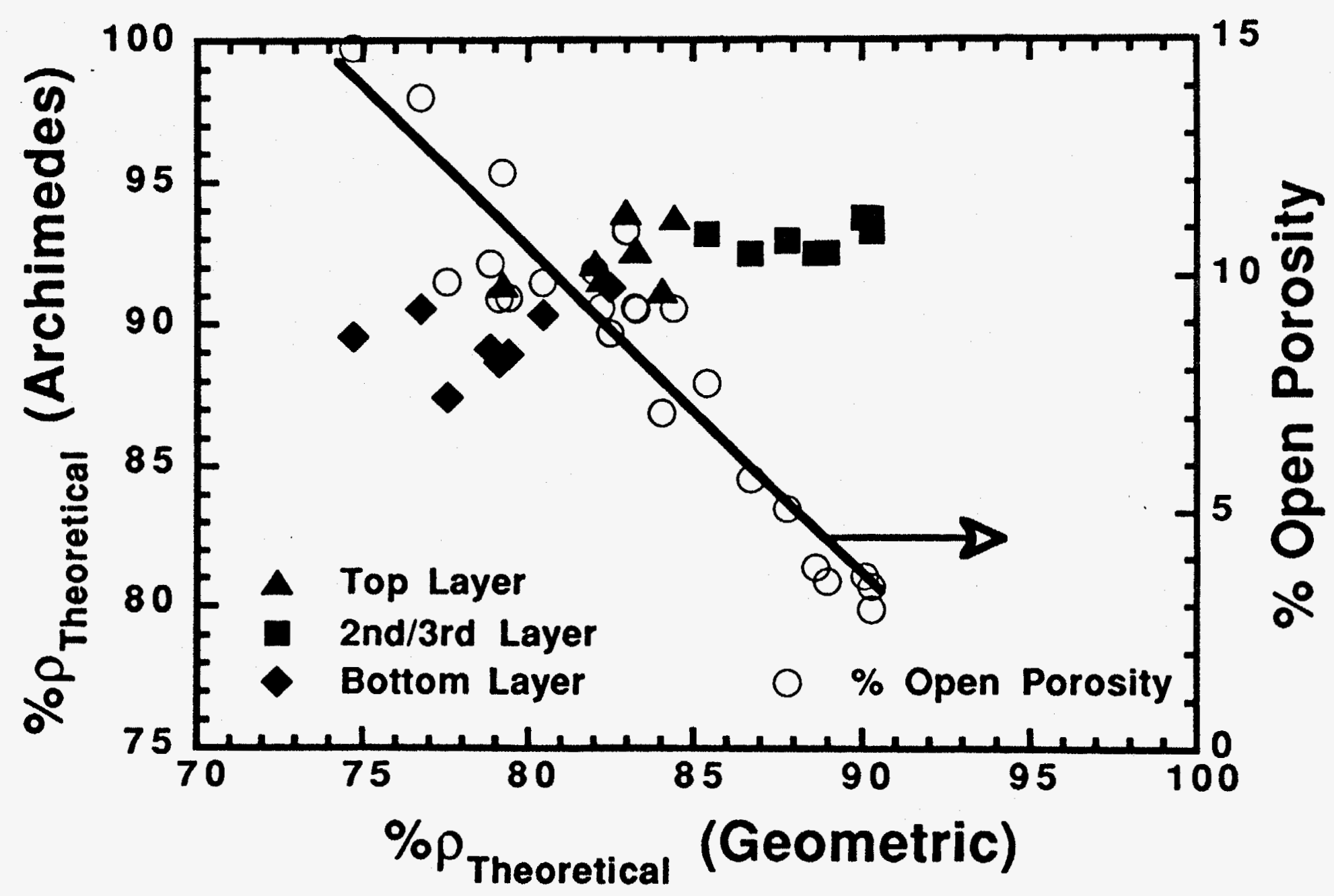




\section{ELASTIC MODULUS PROPORTIONAL TO DENSITY}

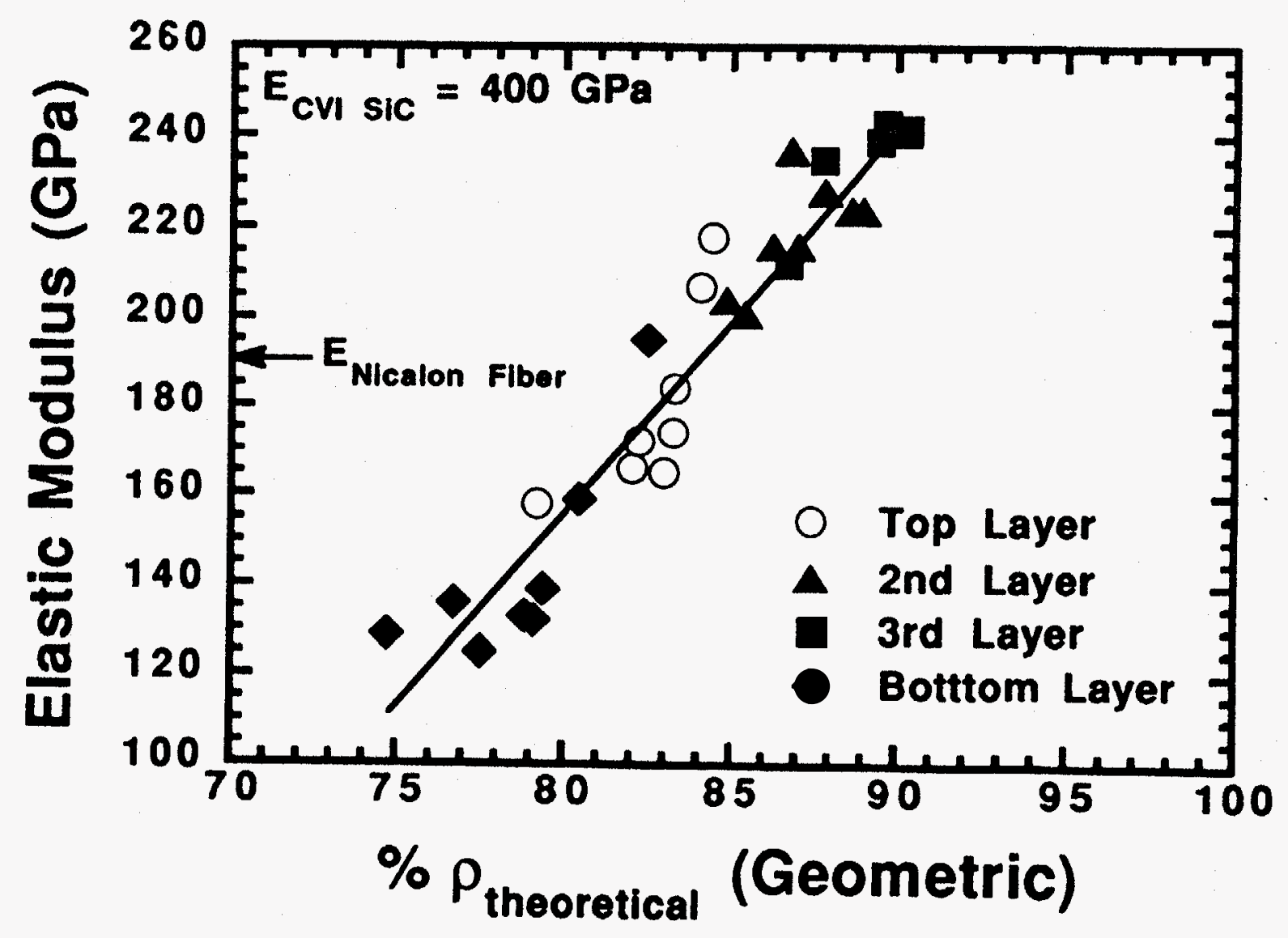




\section{Flexural Strength versus Composite Density}

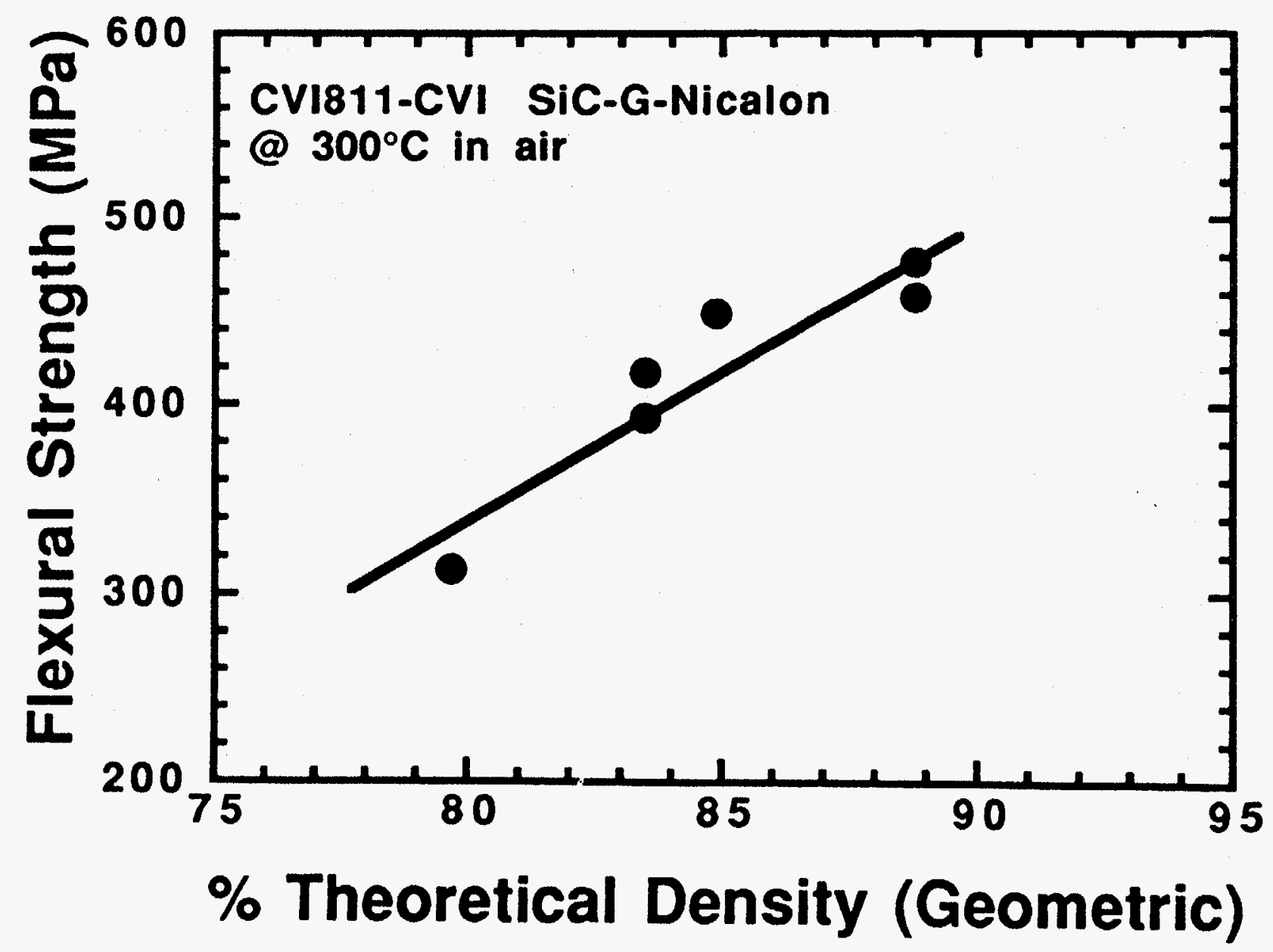

